\title{
La reconfiguración espacial y sus implicancias socio-ambientales de la ciudad de Chachapoyas, departamento de Amazonas
}

Artículos originales: GEOGRAFÍA

Recibido: 20/04/2021

Aprobado: 25/06/2021

Publicado: 14/10/2021

\author{
Miguel Ángel Comeca Chuquipul \\ Universiddad Nacional Mayor de San Marcos \\ mcomecac@unmsm.edu.pe
}

\begin{abstract}
RESUMEN
Chachapoyas es una de las primeras ciudades coloniales fundadas por los españoles en el Perú, su ubicación estratégica para colonizar la selva fue al parecer la justificación inicial de su fundación. Su estructura urbana colonial de trazo tradicional ha perdurado por más de cuatrocientos ańos sin sufrir grandes modificaciones; sin embargo desde finales del siglo XX a la actualidad la ciudad soporta una continua presión demográfica, estando considerada actualmente entre las cinco ciudades con mayor crecimiento poblacional en el Perú, esta situación está generando un cambio en la dinámica espacial de la ciudad y en su expansión de manera desordenada e informal; en algunos casos ocupando áreas expuestos a peligros físicos, carentes de infraestructura y servicios básicos que les convierte en espacios vulnerables. Esta investigación muestra como la ciudad está experimentando este proceso de reconfiguración espacial diferenciada y el comportamiento que ella genera a través de la descripción y caracterización espacial; además de evidenciar las implicancias de la vulnerabilidad socioambiental de la misma, identificando cuáles son los factores que dan lugar a esta situación.
\end{abstract}

Palabras Clave: Reconfiguración espacial, Vulnerabilidad socio ambiental, segregación espacial, crecimiento urbano.

\begin{abstract}
Chachapoyas is one of the first cities established by the Spanish during the colonial period of Peru, apparently founded as a strategic location to extend territorial control over the Amazon. Its colonial urban structure with a traditional layout has lasted for more than four hundred years without undergoing relevant modifications. However, from the end of the 20th century to the present, the city has endured continuous demographic pressure, currently considered among the five cities with the highest population growth in Peru. This situation is generating a change in the spatial dynamics of the city, with a disordered and informal expansion, in some cases occupying areas exposed to physical dangers, lacking basic infrastructure and services, turning them into vulnerable areas. This research presents how the city is experiencing differentiated processes of spatial reconfiguration and the behaviors it generates through the description and characterization of spaces. In addition, we evidence the implications and identify the factors that explain a situation of socio-environmental vulnerability.
\end{abstract}

KeYwords: Spatial reconfiguration, socio-environmental vulnerability, spatial segregation, urban growth. 


\section{Introducción}

L a ciudad de Chachapoyas es la capital del departamento de Amazonas, se ubica en la parte nororiental del territorio peruano; como tal asume roles importantes como centro político administrativo, comercial, financiero, turístico, convirtiéndose en una ciudad multifuncional, además «su función básica es la de proporcionar bienes y servicios a consumidores que habitan en un espacio determinado que va más allá de sus límites» (Pecht, 1976). Su ámbito espacial abarca 547.17 hectáreas y el área urbana ocupada es de 369.22 hectáreas (PDU de Chachapoyas, 2013); según el censo 2017 cuenta con una población de 32,026 habitantes, su tasa de crecimiento anual durante periodo 1993 al 2007 fue de $2.81 \%$, y entre el 2007 al 2017 se incrementó a $3.3 \%$ anual.

Chachapoyas es una ciudad intermedia, pero en su condición de capital departamental, teniendo en cuenta los roles que cumple descritos anteriormente, sumados a su ubicación estratégica en la parte sur del departamento lo convierte en la principal ciudad cercana y receptora inmediata de población y el centro de intercambios económicos y culturales con el mundo rural a través de las relaciones familiares permanentes y fluidas (Riofrío, 2002).

En el Perú los procesos de migración que priorizaban la gran metrópoli como Lima, en estas últimas décadas han disminuido, por el contrario ciudades pequeñas del interior del país como es el caso de Chachapoyas han tenido un incremento de migrantes que han priorizado las ciudades más cercanas que cada vez tienden a consolidarse, las razones que han dado lugar a estas decisiones de la población migrante, son varias, solo enumeraremos algunas de ellas, como el mercado demandante de bienes y servicios, el crecimiento de la burocracia estatal en su interior, la prestación de servicios como educación y salud, demandante de mano de obra laboral, su cercanía y accesibilidad, entre otras. Esta situación también ha generado que la ciudad sea receptora de actores con diversidad de intereses, convirtiendo a la misma en un entorno dinámico y en constante cambio, que a la vez impulsa a los sujetos a adecuarse continuamente a nuevos escenarios (Borrayo, 2012).

Sin embargo, cuando se habla de desplazamiento poblacional a ciudades intermedias como es
Chachapoyas, la población migrante ingresa y sale de las ciudades, mientras que los que se establecen utilizan estrategias múltiples; este dinamismo generado al interior de la ciudad tiene una relación directa a su entorno inmediato, en función a una estructura de «ramilletes urbanos» (DESCO, 2004)

Esta manera de poblamiento ha tenido un impacto en las nuevas formas de reconfiguración o morfología urbana de la ciudad, si tomamos en cuenta que estos fenómenos van ocurriendo en contextos temporales, históricos, económicos, políticos, culturales, sociales y otros, sin embargo, quedan impregnados en la memoria de la ciudad, como capas que se superponen y que se reconstruyen constantemente sobre sí misma a través del tiempo (Borrayo, 2012).

En este contexto la presión demográfica hacia la ciudad de Chachapoyas se ha incrementado en estos últimos años, ocasionando que su expansión urbana haya generado una nueva reconfiguración hacia la periferia de manera desordenada e informal, ocupando espacios expuestos a un alto nivel de peligros físicos, así mismo se ha incrementado la demanda de vivienda y valor de la tierra urbana; y, por tanto el requerimiento de mayores servicios básicos e infraestructura urbana, que en muchos casos no han sido cubiertos.

La presente investigación pretende realizar un análisis inicial de identificación, descripción, diferenciación y caracterización espacial de la reconfiguración de la ciudad; además de mostrar cómo se expresa la vulnerabilidad socioambiental en ella, así como explicar cuáles son los factores que dan lugar a esta situación.

\section{Metodología}

La presente investigación toma como ámbito espacial la ciudad de Chachapoyas, temáticamente se abordará la reconfiguración o dinámica espacial de la ciudad y sus implicancias a través del análisis de la vulnerabilidad socioambiental; por lo que lo hemos definido que el nivel de esta investigación es de tipo descriptiva y explicativa.

El procedimiento metodológico en la investigación, de manera resumida, consistió, primero en la recolección de información bibliográfica de la temática del estudio, así como la recolección cartográfica del área de estudio para la elaboración del mapa base 
de la ciudad de Chachapoyas; seguidamente en la fase de gabinete se ordenó y clasificó la información con el apoyo de la cartografía temática con la finalidad de tener el análisis espacial de la ciudad.

Seguidamente se identificó los asentamientos poblacionales que forman parte de la expansión de la ciudad y que dan lugar a la nueva reconfiguración de la ciudad, asimismo se cuantificó las áreas críticas con vulnerabilidad socioambiental en la ciudad, evaluando que factores condicionan esta situación.

Para lo cual se desarrolló el trabajo de campo en el ámbito espacial de la ciudad, donde se identificó las áreas críticas o con vulnerabilidad socioambiental, además de contrastar la información previa que se tenía mediante otras fuentes, para lo cual se utilizó las técnicas de la observación, descripción y ejecución de encuestas y entrevistas a la autoridad y funcionarios de la municipalidad provincial de Chachapoyas, dirigentes de los asentamientos humanos y población involucrada en el área de estudio.

\section{Resultados}

\subsection{Características generales de la ciudad de Chachapoyas}

La ciudad de Chachapoyas se encuentra ubicada en la parte nororiental andina del territorio peruano sobre un territorio accidentado, cuya altitud promedio es de 2,334.00 m.s.n.m., sin embargo las altitudes extremas fluctúan entre los 2100 a 2600 m.s.n.m. en las partes bajas y altas respectivamente, quedando delimitada hacia el norte con terrenos empinados de la comunidad de Huancas; por el este también con terrenos de la comunidad de la misma comunidad, tomando como referencia la quebrada Santa Lucía, tanto en la parte alta como baja; hacia el sur está delimitado con el cerro Puma Urco sector el Molino, carretera Pedro Ruiz - Chachapoyas; al lado oeste con el fundo Bocanegra, parte del Sector el Molino y quebrada Yurac Urco (PDU de Chachapoyas, 2013)

Chachapoyas fue fundada por don Alonso de Alvarado el 5 de setiembre de 1538, inicialmente en el poblado que hoy corresponde a la Jalca y, posteriormente fue trasladada al pueblo de Levanto. Dos lugares ubicados a mayor altitud con una topografía más accidentada en relación con la ubicación actual de la ciudad, con condiciones climáticas difíciles que restringieron su ocupación y expansión espacial. Debido a ello la capital fue trasladada al sitio donde actualmente ocupa el año 1546. Lugar también accidentado, pero con mayor amplitud espacial tanto para la edificación y expansión de la ciudad, así como para el desarrollo de la actividad agrícola en las áreas periféricas, indispensables para el sostenimiento de la ciudad, además de concentrar a mayor cantidad de indígenas, que era importante en la idea inicial de sus fundadores de convertirla «como centro de operaciones militares y religiosas hacia oriente peruano" (Limachi, 2010).

La ciudad antigua o tradicional fue concebida para su edificación por los españoles tomando en cuenta su relieve irregular, con una estructura inicial de corte de damero con "una plaza, donde haya iglesias y casas de Cabildo, calles rectas y abiertas a los vientos y a la defensa» (Pech, 1976, citando Cerda Ibánez); siguiendo esta estructura de corte colonial rectangular, su expansión ha sido lenta hasta casi fines del siglo XX (ver fig. 1).

Posteriormente la dinámica de la ciudad ha sufrido cambios acelerados, desarrollándose un crecimiento de manera desordenado e informal, con proyección hacia los contornos de forma radial e irregular, condicionado por factores entre los que podemos mencionar de manera general: a su topografía agreste conformado por laderas, cerros, quebradas, en algunos casos con fuertes pendientes; carencia de planes de crecimiento urbano ordenado; vacíos legales en la propiedad de las tierras; indefinición limítrofe distrital, invasiones de tierras con fines de vivienda, entre otros.

Este proceso de crecimiento acelerado ocurre en Chachapoyas desde finales del siglo XX, acrecentándose estas últimas décadas, donde existe una creciente demanda de espacios para la vivienda de la población que ha migrado a la ciudad para establecerse; esta población procede de pueblos pequeńos del interior de los distritos y provincias del departamento de Amazonas así como de otras regiones como Cajamarca. La gran mayoría de ellos se han establecido en los nuevos asentamientos poblacionales ubicados en la periferia de la ciudad, como es el caso de los asenta- 


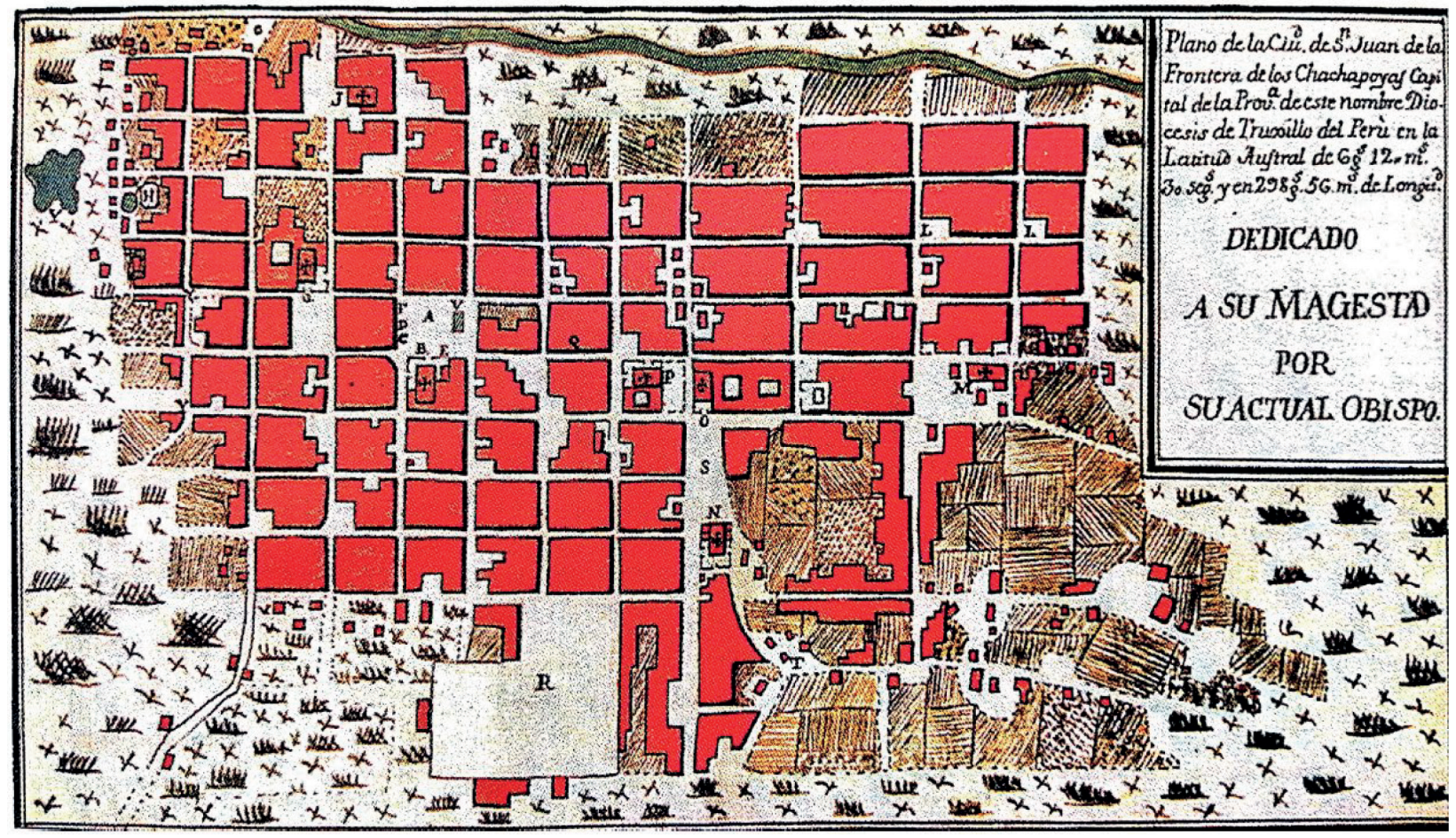

Figura. 1. Plano de la ciudad de Chachapoyas de 1782, elaborado por el Obispo Baltazar Jaime Martínez Fuente: Imagen tomada de Huamán Herrera Carlos. Chachapoyas en el tiempo.

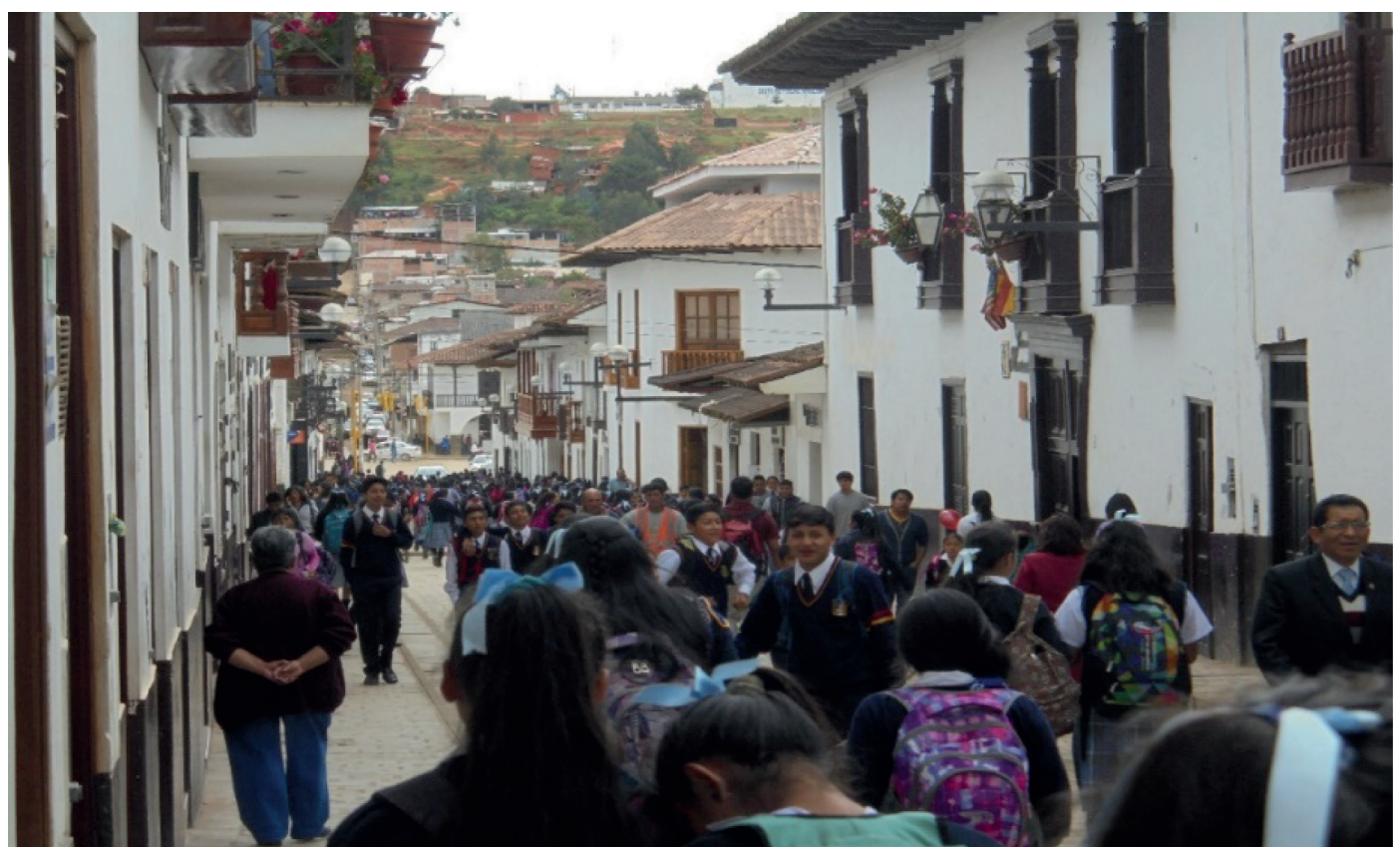

Figura 2. El tradicional Jirón Amazonas, lugar central de la ciudad de Chachapoyas

mientos Humanos, Señor de los Milagros, Santa Rosa de Lima, Murcia, Pedro Castro Alva y 16 de Octubre en la parte norte; Toribio de Mogrovejo, Santa Rosa de Luya Urco al lado oeste; Virgen de Asunta, el Molino al lado sur y suroeste de la ciudad (ver fig. 5).

\subsection{Proceso de reconfiguración de la ciudad}

La ciudad actual mantiene su característica tradicional de corte colonial, sobre todo en la zona central donde en el entorno de su plaza de armas se ubican los principales locales públicos, como la municipali- 


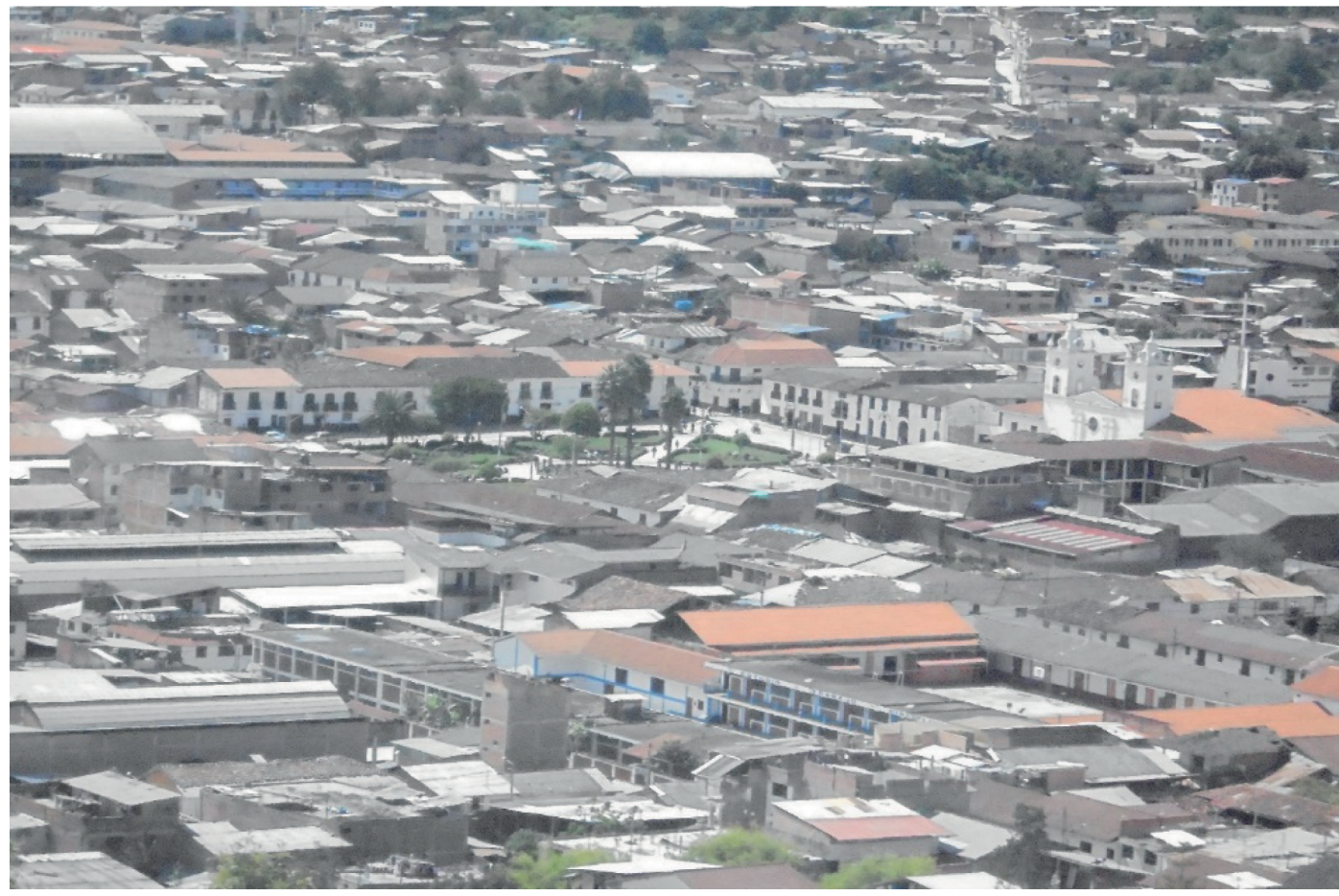

Figura 3. Plaza de armas y parte del área central de la ciudad

dad provincial, la catedral, la gobernación entre otras; su prolongación se dio a través de calles angostas que fluctúan entre 4 a $6.5 \mathrm{~m}$ de ancho. Así mismo la característica de las viviendas que conforman esta parte central de la ciudad, es de una arquitectónica correspondiente al siglo XIX e inicios del XX, de configuración homogénea con casonas amplias que generan una agradable perspectiva simétrica en las principales calles de la ciudad, como los jirones Amazonas, Ayacucho, Grau, Ortiz Arrieta, entre otros; donde destacan los balcones de madera tallada que sobresalen de los muros de estas edificaciones. Esta parte central o zona monumental de la ciudad aún mantiene el corte tradicional de la denominada «Fidelísima ciudad de Chachapoyas» (ver fig. 2).

Para una mejor caracterización de la ciudad, hemos distinguido dos grandes áreas espaciales diferenciadas, que a continuación describiremos:

El área del cercado, zona monumental o tradicional de la ciudad. Correspondería a la ciudad antigua tradicional conformada por viviendas que aún mantienen su corte colonial, teniendo como punto central la plaza de armas. En esta zona se localiza las instituciones públicas y privadas principales, los locales comerciales más importantes y en su área de influencia se desarrolla el comercio ambulatorio de manera informal a lo largo de sus calles principales.
En esta parte de la ciudad es donde se desarrolla el $80 \%$ de la actividad comercial y otros servicios, a través de los mercados, tiendas variadas, restaurantes, hoteles, agencias turísticas, etc., también aquí están asentados las principales instituciones públicas como la municipalidad provincial, el obispado, instituciones educativas de los diferentes niveles, instituciones de salud, etc. Adicionalmente aquí se concentra el mayor grupo de población intermitente no residente de la ciudad pero que lo visita permanentemente por breve tiempo de manera diaria, parte de esta población acude a la ciudad para realizar compras o vender productos, así como también hay grupos continuos que hacen uso de instituciones burocráticas y también población que presta servicio de transporte interdistrital e interprovincial principalmente.

En cuanto a la ampliación de esta parte central o tradicional se ha dado de manera lenta desde la creación de la ciudad expandiéndose siguiendo su trazo rectangular inicial, a través de la incorporación y proyección de sus cuatro barrios tradicionales como son, hacia al noroeste el barrio de Luya Urco, al noreste el barrio de Yance, al suroeste el barrio de Santo Domingo y al sureste el barrio de La Laguna: esta estructura de la ciudad se ha conservado con hasta fines del siglo XX (ver fig. 3). 
Las áreas periféricas de la ciudad. La expansión acelerada de la ciudad empieza hacia fines del siglo $\mathrm{XX}$ a través de una nueva reconfiguración territorial, es decir de forma radial irregular hacia la periferia, mediante la ocupación de los asentamientos humanos en áreas aledañas a las quebradas, así como en las laderas de los cerros y lomas, como Pedro Castro Alva, 16 de octubre, Señor de los Milagros, Santo Toribio de Mogrovejo, Santa Rosa de Lima, Virgen de Asunta y Alonso de Alvarado, entre otros (ver fig. 4 y 5 ).

Este proceso de crecimiento urbano expansivo se ha dado en estas áreas de manera informal y desordenada, carentes de instrumentos de planificación y control urbano de parte del gobierno local. Un indicador que refleja este proceso es la tasa de crecimiento poblacional anual actual de la ciudad, que supera el $3.3 \%$ producto de la migración, sobre todo de población joven, que procede de ciudades y poblados cercanos, condicionado por factores como: la creación el año 2000 de la Universidad Nacional Toribio Rodríguez de Mendoza y su posterior ampliación de más especialidades, que en la actualidad alberga una población estudiantil aproximada de 3000 estudiantes; además de la apertura de universidades particulares, y el funcionamiento de las sedes de Instituciones como Gobierno Central y Gobierno Regional.
Este proceso expansivo viene ocasionando problemas en la ciudad relacionados con la ocupación informal y no planificada de su territorio, degradación más incesante de su entorno natural, carencia de espacios públicos como parques y áreas verdes, deficiencias en servicios de infraestructura básica y seguridad a la población, que afectan su desarrollo urbano. Otros factores que se puede añadir en la ocupación informal de la ciudad sobre todo en la zona norte, es la existencia de problemas de indefiniciones limítrofes distritales entre Chachapoyas y Huancas, conflictos legales en la posesión de tierras, lo que ha originado la ocupación de las áreas contiguas a la Quebrada Santa Lucía, generándose problemas de posesión y entrampamientos administrativos y legales con la municipalidad provincial, en el otorgamiento de licencias tanto de edificación, certificados de posesión, tramitación de servicios básicos; esta situación afecta negativamente a la población que está asentada en estas áreas.

Asimismo, la construcción de viviendas en zonas de riesgo carentes de control y un plan de ordenamiento urbano, sitúa a la población en un alto grado de vulnerabilidad. Como se puede apreciar estas construcciones están relacionadas con problemas físico-ambientales y urbanos de la ciudad, que, añadido a una configuración topográfica accidentada, consti-

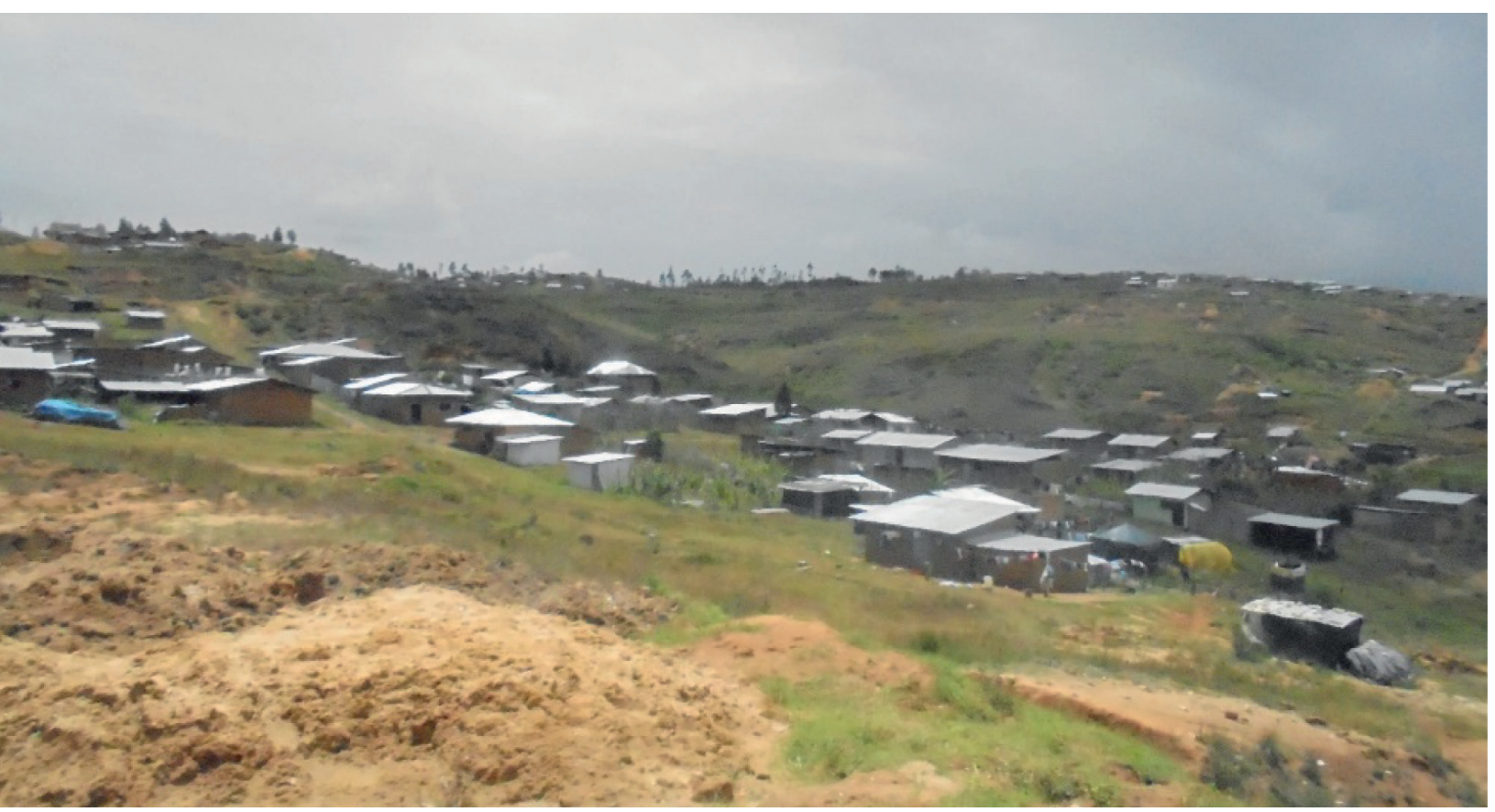

Figura 4. Expansión informal hacia la periferia norte de la ciudad 


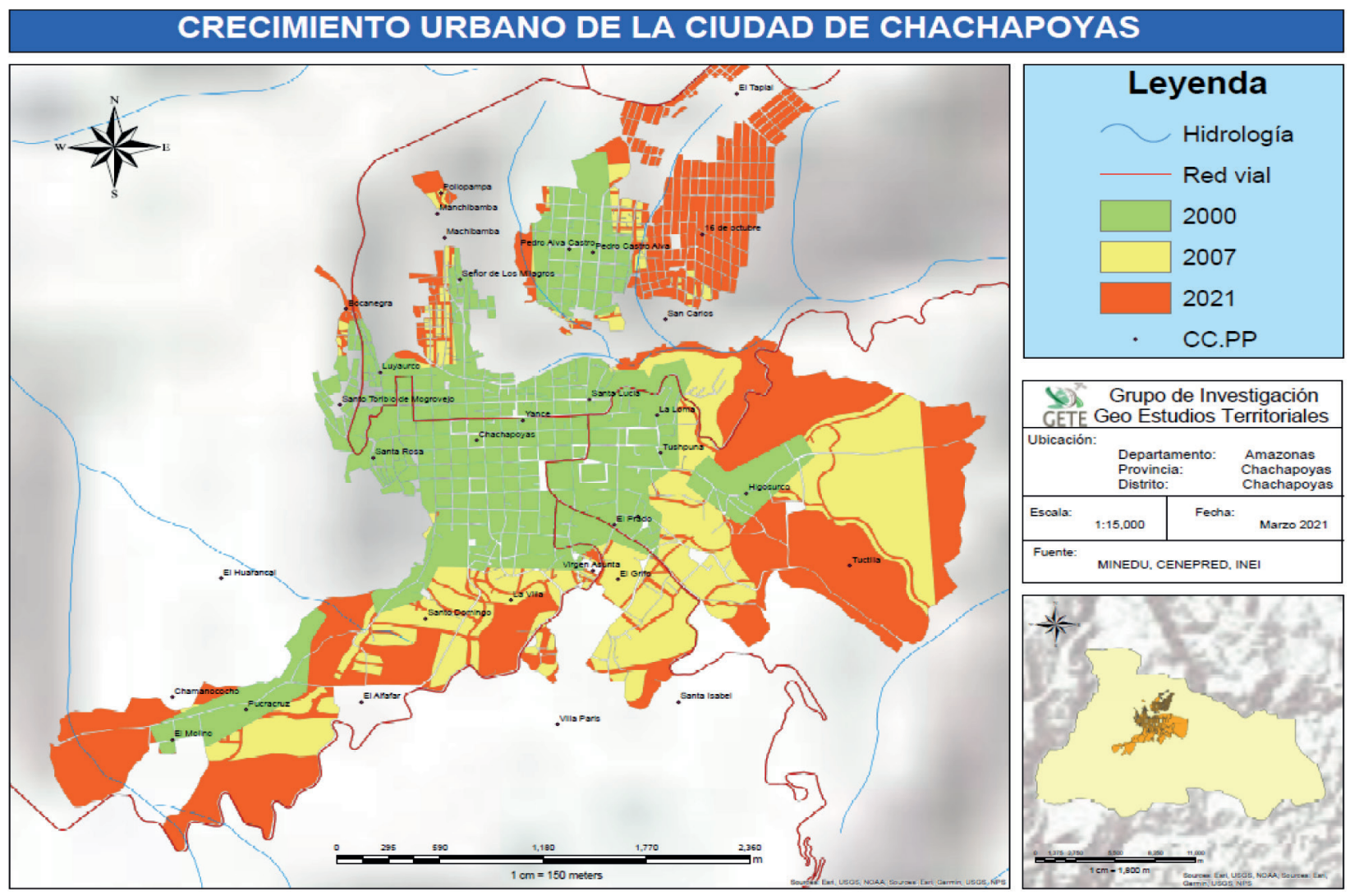

Figura 5. Crecimiento urbano de la ciudada de Chachapoyas

tuye una problemática de seguridad física significativo que existe en Chachapoyas, lo cual impide tener un desarrollo socio-urbano armónico y homogéneo.

Esta manera de expansión urbana desordenada de la ciudad carentes de habilitaciones urbanas, con déficit de servicios básicos, está generando un inicial desencuentro en la pérdida de estabilidad y cohesión social, generada por la separación espacial de grupos segregados socialmente ya sea por sus ingresos que perciben, trabajo o carencia de la misma; esta población en situación de pobreza, además carece de inversión sobre todo en infraestructura y equipamiento básico de servicios por parte del estado.

Sin embargo la dinámica y crecimiento poblacional se sigue incrementando debido al crecimiento natural de la ciudad así como al factor migratorio, tal como muestra los últimos censos oficiales, donde Chachapoyas tuvo un incremento poblacional de 15,785 a 23,202 habitantes entre los censos de 1993 y el 2007; en la actualidad según el censo del 2017 cuenta con 32,026 habitantes; este incremento coincide con el avance espacial de la ciudad mediante la ocupación de los nuevos asentamientos humanos, tal como se puede apreciar en el mapa adjunto, elaborado superponiendo tres momentos temporales con el apoyo de imágenes satelitales (ver fig. 5).

Ahora si evaluamos cual es el papel que cumple la ciudad de Chachapoyas en el sistema de redes es decir la relación interurbana, vemos que ha cobrado dinamismo y fuerza incorporando o generando una relación ciudad y su entorno rural, además la ciudad está articulada vialmente a las capitales de los principales centros poblados de su provincia, así como a las capitales provinciales del departamento, ciudades importantes fuera del departamento como Cajamarca, Jaén, Chiclayo, Rioja, Moyobamba, Tarapoto, etc.

\subsection{Implicancias socioambientales de la ciudad de Chachapoyas}

Hay dos grandes aspectos que también abordaremos en la dinámica que se ha generado en Chachapoyas, de acuerdo a lo que hemos descrito anteriormente; por un lado a través del análisis del grado de vulnerabilidad social, veremos las implicancias en la reestructuración social de la ciudad de Chachapoyas; y 
por otro lado, evaluaremos como los condicionantes geográficos presentes en este ámbito territorial tiene implicancias en la seguridad física, a través de la vulnerabilidad ambiental de la ciudad.

\subsubsection{Manifestación espacial de la vulnerabilidad social}

Asumiendo que la vulnerabilidad social se puede expresar históricamente como los territorios habitados que han reflejado jerarquías y diversos grados de segmentación de su población resultado de contextos políticos, económicos y sociales; esta situación se podría explicar por un lado a través del patrón o modelo económico de desarrollo globalizado vigente, pero también se puede explicar por la incapacidad de los sectores más vulnerables de la sociedad para hacerlos frente, detenerlos o aprovechar beneficios de ellos, que están expresados en una débil organización (Bello, 2010).

En los centros urbanos como Chachapoyas son espacios donde se puede apreciar este fenómeno, a través de manifestaciones como la desterritorialización, la desigualdad económica, la pérdida de identidad propia y la incorporación de otras, segregación social, incapacidad de respuesta del estado que estén expresados en propuestas planificadas de crecimiento ordenado de las ciudades, entre otros.

En ese sentido, la ciudad como receptor de grupos humanos donde se establecen individuos socialmente heterogéneos, da como resultado una diversidad socio espacial, pues la ciudad es el producto de la confluencia de parámetros físicos, sociales y personales (Bello citando a Wirth).

Por lo que se puede entender que la vulnerabilidad social tendría dos componentes explicativos. Por un lado, la indefinición e inseguridad que experimentan las familias e individuos en su condición de vida como consecuencia del impacto provocado por el desarrollo vigente u otros eventos como el económico social de carácter traumático. Por otra parte, el manejo de recursos y las estrategias que utilizan las, familias y personas para enfrentar los efectos de ese evento (Pizarro, 2001).

En el caso de la ciudad de Chachapoyas estas últimas décadas, está experimentando un crecimiento urbano con la llegada de población migrante atraída por los nuevos roles que asume la ciudad, pues acuden individuos y grupos sociales diferenciados tan- to del mismo distrito, provincia y departamento; así como también de otros lugares fuera del departamento, con una diversidad de estilos de vida, intereses, costumbres, patrones culturales, oportunidades laborales, pero que tienen que convivir en la ciudad en muchos casos de manera muy desigual para el logro de un desarrollo social y personal.

Así se observa en Chachapoyas como las fragmentaciones espaciales, tal es el caso de la ciudad antigua céntrica o del cercado, «aún se conservan las viejas casonas solariegas que mantiene ese aire hispano-colonial» (Huamán, 2009), con viviendas amplias que pertenecen a algunos grupos familiares originarios de Chachapoyas quienes conservan costumbres tradicionales, que a la vez le dan un sentido de posesión a la ciudad. Por otro lado, los asentamientos humanos de reciente creación sobre todo en la zona norte han ampliado la extensión de la ciudad ocupando cerros, laderas y bordes de las quebradas que rodean la ciudad, están ocupadas en su mayoría por familias migrantes del interior del departamento y de otros lugares del país, que en muchos casos no son muy bien vistos por las familias tradicionales de Chachapoyas. Esta situación se hace evidente en las maneras e intensidades diferentes de cómo sus habitantes acceden a los programas económicos, a la participación social, a la producción y consumo del producto cultural.

De manera que esta situación en Chachapoyas se evidencia en sectores, como los asentamientos humanos de la zona norte de la ciudad, con la existencia de una situación de segregación y exclusión, fenómenos que pueden identificarse a través del déficit de acceso a los servicios como educación donde los jóvenes tienen que recorrer grandes distancias en muchos casos caminando para asistir a colegios de primaria y secundaria; déficit de establecimientos de salud; además de una infraestructura vial deficiente no asfaltada al interior de estos asentamientos que dificulta el transito fluido de personas y vehículos; carencia de servicio de agua y desagüe domiciliario, lo que dificulta que tengan la calidad ambiental adecuada sus habitantes.

\subsubsection{Caracterización de la vulnerabilidad ambiental de la ciudad de Chachapoyas}

La vulnerabilidad como concepto amplio abarca múltiples connotaciones, puede tratarse de personas, 
de grupos sociales o infraestructura física. Su definición latina es que puede ser herido o sufrir daño. En esa mirada se puede definirlo como el grado de propensión a sufrir daño a consecuencia de un fenómeno de origen natural o humano (PDU de Chachapoyas, 2013); llevado a una ciudad la población esta propensa a sufrir diversos fenómenos que podrían generar graves pérdidas o perturbaciones en la vida cotidiana debido a eventos climáticos o geológicos. Estudios realizados al respecto seńalan que los niveles de riesgo se han incrementado en las últimas décadas, más que por el incremento de la peligrosidad, es por la manera de ocupación y utilización del territorio con altos niveles de exposición (Cardoso, 2017). En la actualidad se enfatiza en hablar de gestión del riesgo como instrumento para disminuir el impacto de los desastres, donde se pone énfasis en la vulnerabilidad como el elemento principal donde intervienen las políticas (Viand, 2015), por lo que cobra importancia la realización de estudios que identifiquen las diversas dimensiones de la vulnerabilidad en un territorio concreto como es el caso de Chachapoyas, con la finalidad de reducir estos niveles y proponer una distribución más adecuada de la ciudad, en cuanto a dotar de servicios básicos e infraestructura que propenda al desarrollo social y mejora de las condiciones de vida.
En ese sentido la ciudad de Chachapoyas presenta algunas de estas dificultades de vulnerabilidad, como el estar emplazada, sobre una superficie con una topografía irregular, con presencia de cerros, lomadas y muchas quebradas, sobre todo en las áreas periféricas de la ciudad. Este substrato agreste al ser ocupados por la población, está expuesto a erosión pluvial del suelo, deslizamientos, inundaciones, etc., debido a la presencia de constantes y fuertes precipitaciones que caen en Chachapoyas. La conformación de esta topografía accidentada de la ciudad, queda manifestada en las oscilaciones en cuanto a altitudes que varía de 2,320 m.s.n.m. en las partes más bajas zonas profundas de las quebradas; la plaza principal alcanza un nivel intermedio a 2,335 m.s.n.m. y en el lado norte el asentamiento humano Pedro Alva Castro alcanza una altura promedio de 2,475 m.s.n.m.

Sin embargo a pesar de estos condicionantes topográficos aún se puede rescatar en Chachapoyas la presencia de un manto verde a los bordes de la ciudad integrado por cultivos agrícolas que se localizan en la parte sur y este de la ciudad, así como pequeños bosques de eucalipto ubicados indistintamente en la periferia de la ciudad, además de la imponente vegetación de los bosques de neblina presentes en el cerro Puma Urco principalmente, lo cual permiten contar con microclimas agradables y espacios con valor paisajístico.

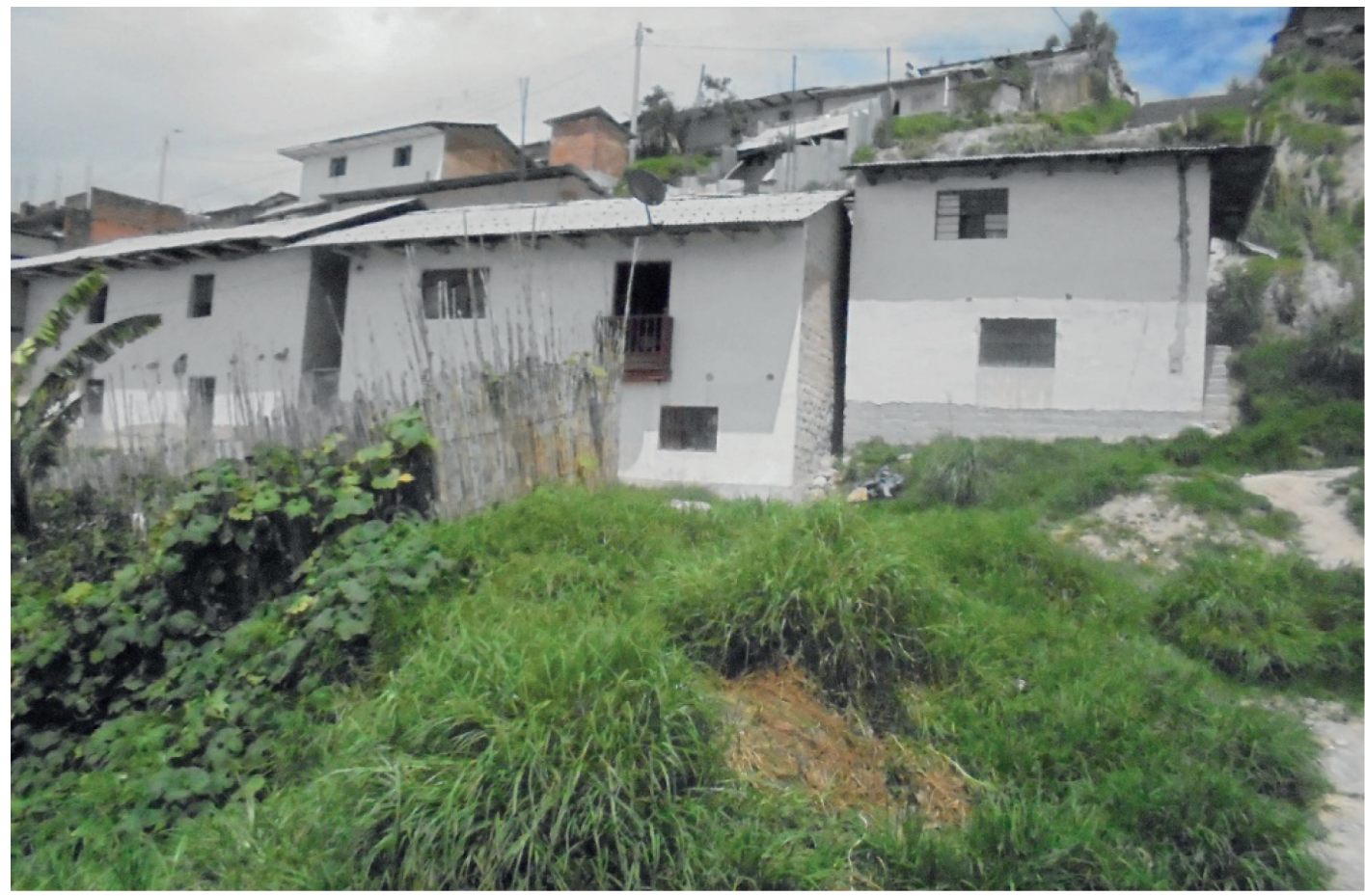

Figura 6.

Viviendas construidas en zonas de fuerte pendiente, cerro Luya Urco 
Además, la ubicación de la ciudad en la vertiente nororiental del territorio peruano cercana a la zona ecuatorial, condiciona un clima templado cálido y ligeramente húmedo con temperaturas de $14.7^{\circ} \mathrm{C}$ en promedio anualmente, con precipitaciones continuas a lo largo del ańo siendo la precipitación promedio de $868.1 \mathrm{~mm} /$ año (PDU de Chachapoyas, 2013), donde alcanza sus más altos valores los meses de noviembre a marzo, con caídas de constantes y copiosas lluvias que son un peligro para la ciudad. La vulnerabilidad se hace evidente si a esta condición climática se añade la ocupación informal de la población de estas áreas agrestes de pronunciadas pendientes, para la construcción de sus viviendas, sobre todo en las áreas periféricas de la ciudad; pues el resultado es la conversión en zonas con alto grado de vulnerabilidad ante la ocurrencia de estos eventos naturales (ver fig. 6).

Por otro lado, otro fenómeno natural considerado como peligro que tiene una presencia constante en diferentes épocas, son los movimientos sísmicos que afectan al departamento por ende la ciudad, es importante tenerlo presente sobre todo para la opción de políticas públicas que mejoren la capacidad de resiliencia de la población ante la ocurrencia de estos fenómenos. Los sismos presentes en nuestra área de estudio están relacionados a la presencia de dos fallas estructurales activas localizadas, una en Cajamarca y la otra en San Martín denominada falla de Moyobamba (Gerencia de Planeamiento y Acondicionamiento Territorial) e (Isabel Bernal, 2002).

Asimismo, la estructura geológica donde se asienta la ciudad de Chachapoyas está compuesta en gran parte por rocas calizas, sumidos a constantes procesos de cambios mineralógicos debido a constantes procesos físicos, químicos y precipitaciones constantes, que disgregan las rocas areniscas presentes y producen la disolución de carbonatos de calcio. Además, presenta una diversidad de suelos arcillosos de baja a media plasticidad; concentrados al norte de la ciudad.

Se puede ver que la constante presencia de fuertes precipitaciones sobre todo temporales en la ciudad es el agente geológico condicionador del paisaje a través de la erosión física y la meteorización química, que altera la composición química de las rocas y el transporte de materiales: pero además el impacto es mayor si se presenta el condicionante de un mal drenaje que es lo que ocurre en algunos sectores de la ciudad.
Por otro lado, la actividad antrópica es causante de la permanente deforestación en las zonas altas con mayores pendientes al norte y noreste de la ciudad, mediante la tala de árboles y arbustos, facilitando los procesos de erosión y desestabilización de los suelos, lo cual acrecienta problemas de seguridad física; como la excavación de cauces artificiales para evacuar aguas residuales que producen contaminación ambiental y alteración del relieve natural del suelo.

\section{Niveles de vulnerabilidad en la ciudad}

Teniendo en cuenta estas consideraciones, se han clasificado tres niveles de vulnerabilidad ante fenómenos naturales que están relacionados a peligros de origen geológico y climatológico, que expresan en gran parte la vulnerabilidad ambiental. A continuación, describimos cada nivel de vulnerabilidad, acompañado del mapa de vulnerabilidad de la ciudad de Chachapoyas adjunto (ver fig. 7).

Nivel medio. Espacialmente correspondería el área central de la ciudad que topográficamente presenta un relieve medio accidentado, sin embargo, esta área es donde está concentrada la mayor infraestructura construida como pistas asfaltadas, canaletas de drenaje infraestructura de alcantarillado que en suma contribuyen a reducir el grado de vulnerabilidad; así mismo están comprendidos también la zona sureste y la parte periférica al este de la ciudad con una topografía relativamente de menor pendiente.

Nivel alto. Corresponde a las áreas prácticamente que circundan el área monumental o central de la ciudad áreas con mayor pendiente que se ubica en la parte norte como, Pedro Castro Alva, Señor de los Milagros, Murcia al noroeste de la ciudad como Alonso de Alvarado, Santo Toribio de Mogrovejo, Luya Urco, que presentan fuertes pendientes proclives a escorrentía pluvial producto de las precipitaciones. También al sureste donde comienza el desnivel hacia abajo adicionado a la carencia de mantenimiento de vías y mal drenaje; por último, al lado sur de la ciudad, hay presencia de suelos de aguas resultado de procesos kársticos.

Nivel muy alto. El primer sector comprende asentamientos de la parte alta del extremo noreste de la ciudad, donde destaca el asentamiento humano 16 de Octubre, sector vulnerable ante la ocurrencia de deslizamientos, por la presencia de suelos arcillosos y fuertes pendientes en su territorio, ante la presencia 


\section{VULNERABILIDAD ANTE FENÓMENOS NATURALES}
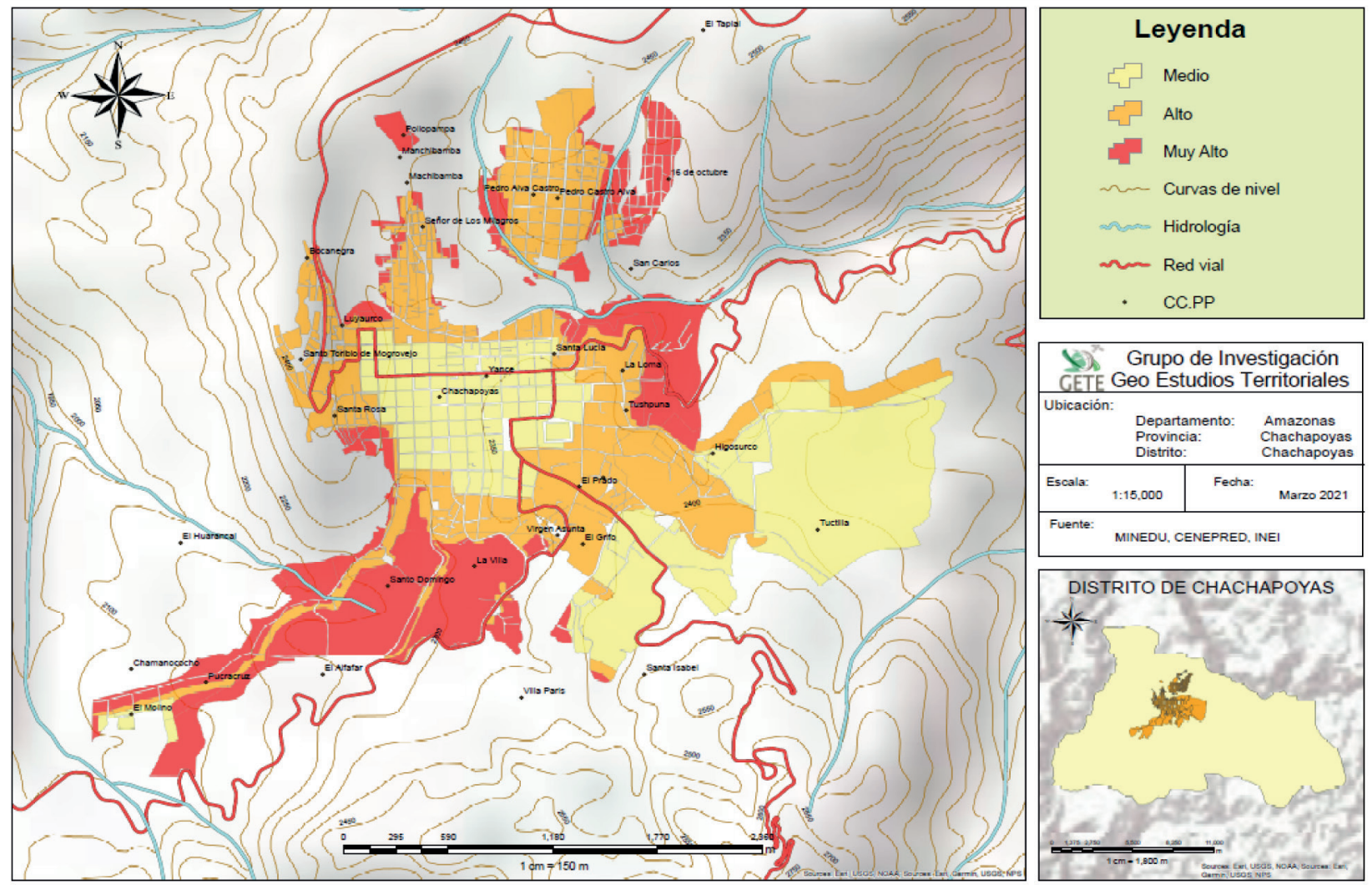

Figura 7. Grado de vulnerabilidad de la ciudad de Chachapoyas

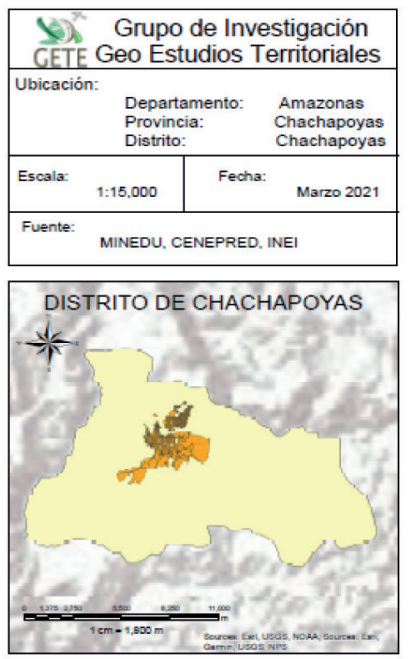

de precipitaciones que constantemente ocurren sobre la ciudad y producen fuertes escorrentías.

El segundo sector comprendido se ubica al este de la ciudad, es la parte baja aledańa a la quebrada Santa Lucía, con presencia de fuertes pendientes y depresión aunada al deficiente drenaje de las viviendas localizadas en las partes superiores.

Luego, el tercero correspondería al lado oeste de la ciudad, los asentamientos humanos Alonso de Alvarado y Santo Toribio de Mogrovejo que se encuentran emplazadas en pendientes bastante pronunciadas.

El cuarto sector es el punto más crítico de la ciudad, se localiza en el sur y suroeste de la ciudad, con la presencia de suelos inestables, deslizables y activos propensos a hundimientos, en sectores como, el sector El Molino, Virgen de Asunta y el Alfalfar.

\section{Impacto ambiental en la ciudad}

Las actividades de origen antrópico al interior de la ciudad que generan impacto negativo son: la emisión aguas residuales sin ningún tratamiento con conteni- do de sustancias químicas desde los hospitales y centros de salud; las actividades de transporte al interior de la ciudad que generan contaminación por la emanación de gases tóxicos como el diésel que tiene un alto contenido de azufre.

En cuanto a la emisión de residuos sólidos Chachapoyas genera un promedio de 13.26 toneladas diarias con un promedio de $0.48 \mathrm{~kg} /$ persona (Zucchetti y Freund, 2018). Se ha podido observar que la disposición final de estos residuos ocurre, se realiza sin ningún tratamiento previo, en un botadero a tajo abierto conocido como o Rondón Pishcopata, los residuos se vierten en la quebrada el Atajo tributario del río Sonche, tiene una longitud de caída de $200 \mathrm{~m}$ aproximadamente (ver figura 8). Los residuos sólidos se votan sin tratamiento previo y de manera superficial lo cual genera contaminación del suelo, el aire, el río Sonche y el Utcubamba colector final río importante del departamento; esta acción ocasiona el deterioro ambiental constituyéndose en foco infeccioso que atentan contra la salud de sus habitantes (PDU de Chachapoyas, 2013). 


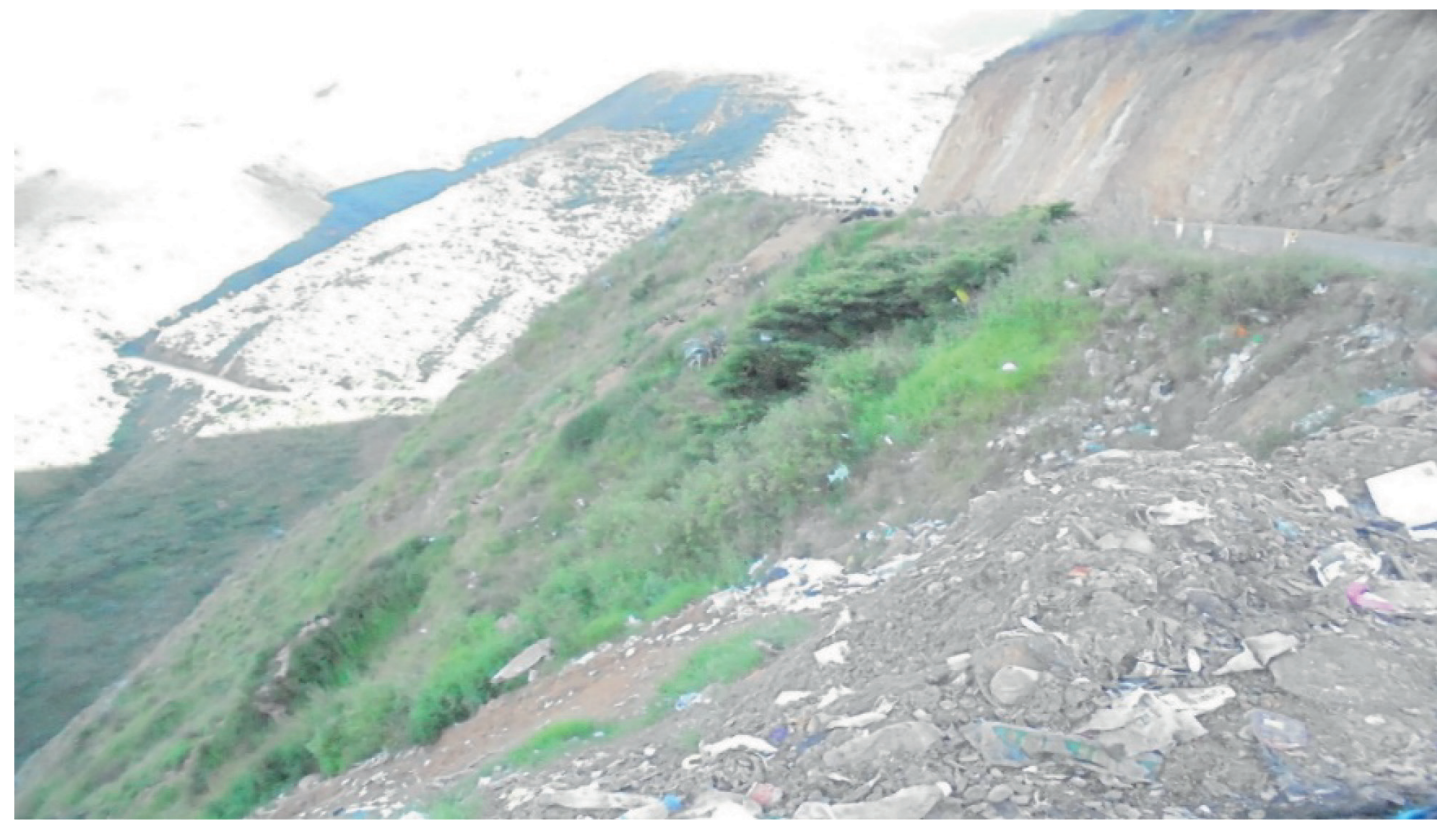

Figura 8.

Botadero

de residuos

sólidos de

la ciudad,

a tajo

abierto de

Pishcopata

\section{Discusión}

Para contrastar la información previa y de campo que teníamos sobre la situación social acudimos a la Municipalidad Provincial de Chachapoyas para recoger su versión, para lo cual entrevistamos al Gerente de desarrollo social, quien nos manifestó que hay áreas marcadas como las periurbanas y los asentamientos humanos, que en los últimos 15 años han expandido el área urbana de manera desordenada e informal, reconociendo que en la actualidad no cuentan con los servicios básicos elementales para su desarrollo.

Así mismo mediante trabajo de campo se ha constatado que la presión por el acceso a la vivienda de la población migrante que vino a Chachapoyas, ha rebasado la capacidad de respuesta por parte de los entes competentes que no han respondido a las exigencias para dotarles de los servicios correspondientes como agua, luz, salud, educación, como sucede con los asentamientos humanos Pedro Castro Alva, Murcia, Nadine I y II y otros. Los programas sociales implementados por el estado como comedores populares o vaso de leche, llegan de manera muy tenue a estos sectores amenguando en parte las deficiencias existentes. Muchos de estos asentamientos poblacionales recientes están comprendidos en un nivel de pobreza y pobreza extrema lo que se puede contrastar con datos del INEI que identifica un $12.3 \%$ de la po- blación chachapoyana en pobreza monetaria, datos que es corroborado con el informe del PNDU, 2012 respecto al IDH de 0.42 que está en la categoría de bajo para la ciudad de Chachapoyas.

Un caso específico que nos llamó la atención es el Asentamiento Humano 16 de octubre, que está asentado en el extremo norte de la ciudad producto de una invasión desde el año 2012, cuenta con una población de 2,000 familias asentadas en terrenos agrestes de pendientes pronunciadas; suelos expuestos a erosión, deslizamientos e inundaciones, sobre todo en temporada de altas precipitaciones Además tienen problemas legales por la posesión de sus tierras para la edificación de sus viviendas, carencia de servicios básicos para su subsistencia, como agua desagüe, luz, servicios de educativos, salud, servicios sociales, etc. tal como manifiestan los pobladores entrevistados. Por lo que lo consideramos como un asentamiento poblacional desprotegido, segregado y altamente vulnerable. En el PDU de la ciudad de Chachapoyas 2013 no está considerado en la propuesta de crecimiento ordenado de la ciudad; sin embargo, comprobamos que este asentamiento forma parte de la convivencia social y económica con la ciudad al margen de su ocupación informal, por lo que la Municipalidad Provincial de Chachapoyas debería propender a su inclusión urbana mediante la formalización y atención ya que es parte de su competencia, en lugar de ignorarlo. 
En cuanto a la seguridad ciudadana en Chachapoyas, la población encuestada relaciona el incremento de la delincuencia con la puesta en funcionamiento el año 2000 del penal de Huancas con alrededor de 600 internos y con la llegada de familiares de los internos de distintos lugares del país a establecerse en Chachapoyas, sin embargo, estos últimos años el fenómeno delincuencial ha disminuido.

Respecto a la tasa de crecimiento poblacional anaual en Chachapoyas sigue incrementandose estando en $3.3 \%$ según censo 2017, si esta tendencia se mantiene lo más probable es que la población de la ciudad se duplique antes de 30 años, lo que significara mayor demanda de terrenos para la edificación de mayores viviendas, por lo tanto, mayor expansión de la ciudad. La demanda desde el 2017 de nuevo suelo urbano en Chachapoyas es de 25.97 ha/año según (Zucchetti y Freundt, 2020); las áreas con mayor viabilidad para considerarse en la expansión urbana corroborado por su Plan Urbano 2013, se encuentra al norte de la ciudad, aledaño al aeropuerto; al este de la ciudad sector el Prado, el Franco, Barrio Tuctilla, el Atajo y circundantes a la Universidad Nacional Santo Toribio Rodríguez de Mendoza, por lo menos en el corto y mediano plazo.

Junto al requerimiento de mayores espacios para la edificación de más viviendas en el futuro, se debe prever las necesidades básicas de atención alimentaria, educación, salud, vivienda, cultura para la población.

En dialogo con el ex Alcalde de Chachapoyas Diógenes Zabaleta, hemos podido comprobar que la Municipalidad Provincial de Chachapoyas cuenta con algunos instrumentos de gestión de la ciudad como son: Plan de Acondicionamiento Territorial, Programa de segregación, Plan Integral de Gestión Ambiental de Residuos Sólidos. Siendo el Plan de Desarrollo Urbano del 2013 el instrumento de gestión más importante con que cuentan la Municipalidad Provincial para el futuro crecimiento ordenado de la ciudad; de todos modos, requiere estar acompańado de voluntad política para implementarlo, actualizarlo y mejorarlo de manera participativa y consensuada con las diferentes organizaciones y actores de la ciudad. Por otro lado consideramos que la municipalidad carece de un Plan de Ordenamiento del Transporte para la ciudad, instrumento básico para garantizar y planificar una mejora del servicio y la infraestructura vial sobre todo en las áreas periféricas, toda vez que la ciudad de Chachapoyas sigue expendiéndose y no cuenta con un servicio de trasporte público de vehículos medianos o grandes al interior de la ciudad, lo que existe es servicio particular de taxis con alrededor de 550 unidades que en muchos casos generan contaminación y congestión vehicular sobre todo en la zona central de la ciudad.

\section{Reconfiguración funcional de la ciudad de Chachapoyas}

\section{Lo económico}

Chachapoyas es una ciudad intermedia pequeña que desde sus fundación se ha caracterizado por el desarrollo de su actividad agrícola y ganadera, como la principal para el sostenimiento de su población residente, a través de la utilización de sus áreas rurales periféricas cercanas a la ciudad, actividad que aún perdura en un gran sector de la población, sobre todo la población que ocupa los asentamientos humanos recientes convirtiendo a la ciudad por un lado morada de descanso, pero por otro lado el lugar de acopio y mercado donde venden sus productos; esta dinámica desarrollada por sus habitantes tiene vinculación con otros pueblos de menor tamaño de la zona y fuera de ella el cual es destacable en cuanto al rol económico que cumple.

Sin embargo, en su proceso evolutivo como ciudad Chachapoyas, además de su condición de capital departamental ha ido convirtiéndose en una ciudad donde el sector terciario cobra gran importancia; así pues según él (PDU de Chachapoyas, 2013) de Chachapoyas, la ocupación económica de la población está distribuida de la siguiente manera, en la actividad comercial el $16 \%$, enseñanza $12 \%$, Administración pública 10.2, agricultura 10.5\%, construcción $9 \%$ y transporte $6.5 \%$.

Tal como muestran las cifras, por un lado, la actividad comercial es muy variada que se desarrolla a nivel mayorista y minorista en el interior de la ciudad como fuera de ella; también es sede de instituciones públicas del nivel nacional, regional y local, donde laboran trabajadores procedentes de diferentes lugares del país, permaneciendo temporalmente, de lo cual se puede inferir que de los ingresos generados en la ciudad no siempre todo retorna a dinamizar la economía local. Sin embargo, se puede decir que un buen porcentaje de familias que ocupan los recientes 
asentamientos humanos dependen del campo y responden a una economía de subsistencia.

La actividad terciaria, además de la oferta de servicios educativos superiores que presta la universidad pública Toribio Rodríguez de Mendoza, universidades privadas e institutos superiores, ha generado atractivo y expectativas para la población que migra a la ciudad, como oportunidad para contar con empleo en estas actividades administrativas, comercio informal o en la crianza familiar de ganadería doméstica (DESCO, 2004).

Por otro lado, estos últimos años la actividad turística ha cobrado gran importancia y dinamismo en la ciudad, lo cual queda expresado en el incremento de visitantes turistas, la concentración de los más importantes servicios turísticos del departamento, como las agencias turísticas, agencias de viajes, tours, infraestructura hotelera, restaurantes, que generan ingresos para las empresas dedicadas este rubro y trabajo para un sector de la población. Sin embargo, desde el ańo 2020 esta actividad está siendo altamente afectada producto de la situación generada por la pandemia del Covid-19.

\section{Lo político}

El peso político de Chachapoyas incluso empieza desde su fundación como una de las primeras ciudades fundadas por los españoles en el nororiente peruano, inicialmente como centro militar estratégico y de enlace para la conquista de la selva. Posteriormente también tuvo un rol importante en el proceso para lograr la independencia del Perú siendo sede en la toma de decisiones a nivel regional. Así como también en su territorio se libró la batalla de Higos Urco la más importante de la región. Actualmente como capital departamental cumple el rol político administrativo a nivel departamental, en su territorio están establecidos las sedes de las principales instituciones del estado donde se toman decisiones tanto a nivel central, regional y local. Además, cuenta con la principal universidad nacional del departamento, universidades particulares, institutos superiores, colegios y hospitales, lo que permite a la población local y del departamento tener oportunidades de acceder a estas instituciones a menor costo económico y tiempo, sobre todo a los servicios de salud, educación y centro laboral. Al parecer esta diferencia de costos y acceso en com- paración con las ciudades grandes y distantes como la capital del país, tiene un peso importante en las decisiones de las personas que optan por vivir en la ciudad y en las que han decidido migrar hacia Chachapoyas de los pueblos aledaños pequeños.

\section{Lo cultural}

Chachapoyas está compuesta por pobladores originarios de la ciudad que ocupan las áreas tradicionales antiguas de la ciudad; luego por población reciente migrante del interior y fuera del departamento que ocupan también áreas centrales, así como las áreas de los asentamientos humanos ubicados en la periferia de la ciudad; sin embargo hay un componente de población temporal que corresponde a los trabajadores que laboran en las instituciones públicas establecidas en la ciudad, donde la mayoría de ellos provienen de otros lugares del interior del país. Por último, también componen la población temporal los jóvenes que en gran número estudian en la universidad pública de la ciudad y estudiantes de otras instituciones educativas.

Esta mezcolanza de pobladores que habitan la ciudad actual, es resultado del proceso evolutivo del crecimiento urbano de la ciudad que está generando cierto impacto cultural, como es el desinterés por mantener las costumbres tradicionales, como las fiestas patronales, bailes tradicionales y otras, propias de Chachapoyas, lo que podría conducir a la pérdida de identidad cultural, esta situación se ha podido observar y es preocupación de las autoridades y la población tal como nos han manifestado los entrevistados. De igual modo en cuanto al sentido socio comunal de su organización tradicional de la ciudad a través de barrios, ya se hacen visibles algunos roces y desencuentros con la nuevas organizaciones como los asentamientos humanos o invasiones, que son formas de organización territorial recientes en la ciudad; estos desencuentros tienen que superarse con el dialogo, las capacitación y la inclusión de las diferentes formas de organizaciones presentes para encontrar la cohesión social y convivencia de la ciudad. La introducción de costumbres foráneas a la ciudad producto del libre acceso a la tecnología y la información a través de los medios como la radio, televisión, internet, tienen un impacto mayor en los jóvenes, en ese sentido esta situación plantea a la ciudad nuevos retos en cuanto a las respuestas de las organizaciones sobre todo edu- 
cativas, sociedad civil, gobierno regional, gobierno local, en el contexto de esta nueva convivencia social tomando en cuenta que los intereses, estilos, costumbres ahora es producto de una nueva diversidad de intereses presentes en la ciudad.

\section{Conclusiones}

- Según el Censo 2017 del Perú, la ciudad de Chachapoyas tiene una alta tasa de crecimiento poblacional anual de 3.3\% anual, lo cual se refleja en el acelerado crecimiento urbano informal y desordenado de la ciudad, hacia sus contornos en forma radial e irregular carentes de instrumentos de planificación y control urbano de parte del gobierno local.

- En la ciudad de Chachapoyas, espacialmente se puede distinguir un área central o tradicional de la ciudad donde se localiza las instituciones públicas y privadas principales, y los principales locales comerciales y de servicios de la ciudad. Por otro lado, se distingue otra área de expansión, conformada por los nuevos Asentamiento Humanos emplazados de manera radial e irregular en los contornos de la ciudad.

- La expansión urbana en las áreas periféricas de la ciudad se desarrolla en zonas con un alto nivel de vulnerabilidad ante deslizamientos o hundimientos, relacionado a la presencia de pronunciadas pendientes, suelos arcillosos entre otros. Pero también existe una situación de segregación y exclusión, debido a la carencia de servicios básicos y desatención por parte del estado.

- La zona más crítica que presenta alto nivel de vulnerabilidad física se ubica al sur y suroeste de la ciudad, que corresponde a Virgen de Asunta, El Molino, el Alfalfar, con la existencia de suelos inestables, deslizables sobre todo que se evidencian en hundimientos, sobre todo en la época lluviosa.

- La ciudad de Chachapoyas carece de un sistema de recojo adecuado de residuos sólidos y carece de una planta de tratamiento de aguas residuales, así de una planta de tratamiento de residuos sólidos.

\section{Recomendaciones}

- Ante el acelerado crecimiento urbano de la ciudad, si bien es cierto la municipalidad provincial de Chachapoyas cuenta con un PDU elaborado el 2013, requiere hacer el seguimiento de su implementación, su actualización y corrección de manera participativa con las organizaciones de la ciudad.

- Los programas sociales deberían focalizarse en los asentamientos poblacionales establecidos con altos niveles de pobreza, con la finalidad de disminuir las enormes brechas sociales y económicas.

- Se deben realizar estudios de gestión de riesgos detallados que identifiquen los diferentes tipos de peligros a nivel de toda la ciudad de Chachapoyas, con la finalidad de prevenir y disminuir los impactos que puedan ocasionar debido a eventos naturales u antrópicos.

- Es indispensable contar con un instrumento de reordenamiento y planificación del transporte, en una ciudad en creciente expansión como Chachapoyas.

- Es indispensable la instalación de una planta de tratamiento de residuos sólidos y la construcción de una planta de tratamiento de aguas residuales para la ciudad, para disminuir los impactos ambientales y así mejorar la calidad de vida de la población.

\section{Bibliografía}

Bello SÁnchez, Wiliam, G. R. (2010). La Vulnerabilidad Socio-Ambiental en la evaluación socio-espacial del Centro Histórico de La Habana. Proyección 9. Habitat Urbano: dimensiones y perspectivas, 105-122.

Bernal Isabel, H. T. (2002). Zonas sismogénicas en Perú: Volúmenes de deformación, gráficos polares y zonificación preliminar. Boletín de la Sociedad Geológica del Perú, 31-44.

Borrayo, E. R. (s.f.). Transformación socio-espacial y dinámicas del uso del suelo en Guadalajara, México: Análisis la producción del espacio urbano-metropolitano y sus posibles escenarios. Universidad de Guadalajara. México: Centro de Investigaciones del Medio Ambiente y Ordenamiento Territorial (CIMA). 
Cardoso, M. M. (2017). Estudio de la vulnerabilidad socio-ambiental a través de un índice sintético. Caso de distritos bajo riesgo de inundación: Santa Fe, Recreo y Monte Vera, Provincia de Santa Fe, Argentina. Caderno de Geografia, pp. 156-183.

Collantes Pizarro, Gustavo. Datos Históricos de Amazonas.

DESCO (2004). Perú Hoy. Las ciudades en el Perú. Lima: ali arte gráfico publicaciones.

Dirección General Parlamentaria, Oficina de Gestión de la información Estadística (2012). Carpeta Georeferencial Amazonas.

Ferradas, Pedro. (2012). Riesgos de desastres y Desarrollo. Lima: Soluciones prácticas.

Gerencia de Planeamiento y Acondicionamiento Territorial (s.f.). Plan de prevención y atención de desastres naturales de la región Amazonas. Chachapoyas.

Informe Perú (2011). Vulnerabilidad de las ciudades frente al cambio climático en agua potable y saneamiento. Sociedad de urbanistas del Perú.

Limachi, L. (2010). Socio economía, informe temático. Proyecto Zonificación Ecológica y Económica del de- partamento de Amazonas, convenio entre el IIAP y el Gobierno Regional de Amazonas. Iquitos - Perú.

PDU (2013). Plan de Desarrollo Urbano de la Ciudad de Chachapoyas Municipalidad Provincial de Chachapoyas y Ministerio de Vivienda y construcción y Saneamiento.

Pecht, L. H. (1976). Crecimiento Urbano de América Latina. San José Costa Rica: Centro Latinoamericano de Demografía, 1976.

Pizarro, Roberto (2001). La vulnerabilidad social y sus desafíos: una mirada desde América Latina. La CEPAL.

Riofrío, Gustavo (2004). Pobreza y Desarrollo Urbano en el Perú. DESCO, 2004. Perú Hoy: Las Ciudades en el Perú. Lima, pp. 71-111.

Viand y Briones (2015). Riesgos al Sur. Diversidad de riesgos de desastres en Argentina. Buenos Aires: La Red de Estudios Sociales en Prevención de Desastres en América Latina (LA RED).

XII Censo Nacional de Población y Vivienda del Perú 2017. Zucchetti, Anna y Freund, Daniela (2018). Ciudades del Perú. Primer Reporte Nacional de Indicadores Urbanos 2018. Lima. Perú: PERIFERIA Territorios Vivos. 